\title{
Maternal and Perinatal Outcome Among Pregnant Women with Thrombocytopenia Attending Ibrahim Malik Teaching Hospital- Sudan
}

\author{
Omiema Ibrahim Idris Ahmed ${ }^{1}$, Omer Mohamed Ali Mandar², Rihab Jaafar Ibrahim ${ }^{3}$, Nada Gaafar Hassan ${ }^{4}$ \\ and Siddig Omer Mohamed Handady ${ }^{5 *}$
}

${ }^{1}$ Department of Obstetrical \& Gynecology, Omdurman Maternity hospital, Sudan

${ }^{2}$ Faculty of Medicine, Al gadrif University, Sudan

${ }^{3}$ Department of Obstetrical \& Gynecology, Ibrahim Malik hospital, Sudan

${ }^{4}$ Faculty of Medicine, University of Khartoum, Sudan

${ }^{5}$ Faculty of Medicine, Al Nahda University, Sudan

*Corresponding author: Siddig Omer Mohamed Handady, Associated professor of obstetrics \& gynecology, Faculty of Medicine, Al Nahda University, Khartoum, Sudan.

Received Date: December 28, 2019

Published Date: January 08, 2019

\section{Introduction}

Thrombocytopenia is encountered in $7-8 \%$ of all pregnancies. Thrombocytopenia is second to anemia as the most common hematological abnormality during pregnancy [12]. Thrombocytopenia is defined as a platelet count below 150 $\mathrm{x} 109 / \mathrm{L}$, caused by accelerated platelet destruction or decreased production. It is classified as mild with a platelet count of $100-150 \mathrm{x}$ 109/L, moderate at 50-100 x109/L, and severe with less than 50x 109/L [3-4]. In normal pregnancies $7.6 \%$ of women present with mild thrombocytopenia and $65 \%$ of them will not be associated with any pathology [5]. The most causes of thrombocytopenia during pregnancy were gestational thrombocytopenia about $8 \%$ of all pregnancies and accounts for more than $75 \%$ of cases of thrombocytopenia in pregnancy [3-5]. Platelet counts normalize within 2-12 weeks following delivery. All women with gestational thrombocytopenia had normal platelet counts by the seventh postpartum day [5]. No pathological abnormality for the mother or fetus was noted in gestational thrombocytopenia. Preeclampsia and HELLP syndrome are the second most frequent cause of thrombocytopenia in late second and third trimester, accounting for $21 \%$ of cases of thrombocytopenia at the time of delivery.

ITP seen in $5 \%$ of cases of thrombocytopenia in pregnancy is characterized by a moderate to severe decrease in the platelet count, due to platelet auto-antibodies [6-8]. ITP patients with severe thrombocytopenia require treatment due to risk of maternal hemorrhage and also risk of neonatal thrombocytopenia.
The present paper is focusing to determine the etiologies of maternal thrombocytopenia and determine maternal \& perinatal outcomes compared with normal pregnancy.

\section{Material and Methods}

It was prospective and analytic case control hospital-based study carried out at Ibrahim Malik teaching Hospital, Khartoum State-Sudan during the period from October 2015 to October 2016, (756) pregnant women who attended the antenatal clinic regularly were selected. All women were screened for thrombocytopenia in second trimester (after 20 weeks). Platelet count assessment was done through automated blood count analyzer with routine antenatal hematological evaluation of the patient. Women with normal platelet $(n=677)$ were taken in control group and those with low counts less than $150 \times 109 / \mathrm{L}(\mathrm{n}=79)$ were included in study group, maternal \& perinatal outcomes were assessed.

Detail history including maternal age, obstetric history, previous major illness, any medication history, past and present medical and surgical history was noted. A detailed obstetrics history was obtained and maternal high-risk factors like preeclamsia, eclampsia, DIC, HELLP syndrome etc. were noted. All the cases were followed till delivery to record any complications like preterm labor, abruption, preeclampsia, any other morbidity. Duration of pregnancy at the time of delivery and mode of delivery were recorded. 
Data was entered into SPSS version 22 and analyzed accordingly. The quantitative variables were presented in mean and standard deviation and qualitative variables were presented in frequency and percentages. Important summary statistics were obtained, and associations were examined using chi-square test. Significance level of 0.05 (i.e. $\mathrm{P}<0.05$ ) was used to determine the significance of associations being examined.

Table 1: Types and causes of thrombocytopenia among our study group.

\begin{tabular}{|c|c|c|c|}
\hline \multicolumn{2}{|r|}{ Item } & Frequency & Percent \\
\hline \multirow{4}{*}{ Type of thrombocytopenia } & Mild & 52 & $65.80 \%$ \\
\hline & Moderate & 22 & $7.80 \%$ \\
\hline & Severe & 5 & $6.40 \%$ \\
\hline & Total & 79 & $100.00 \%$ \\
\hline \multirow{8}{*}{ Causes of thrombocytopenia } & Gestational thrombocytopenia & 49 & $62.00 \%$ \\
\hline & Preeclampsia, eclampsia & 17 & 21.5 \\
\hline & Idiopathic thrombocytopenic Purpura (ITP) & 5 & $6.40 \%$ \\
\hline & HELLP syndrome & 4 & $5.10 \%$ \\
\hline & Malaria & 2 & $2.40 \%$ \\
\hline & HIV & 1 & $1.30 \%$ \\
\hline & Acute fatty liver & 1 & $1.30 \%$ \\
\hline & Total & 79 & $100.00 \%$ \\
\hline
\end{tabular}

Table 2: Shows the nonparametric correlation between the two groups regarding demographic data.

\begin{tabular}{|c|c|c|c|c|c|}
\hline & \multicolumn{2}{|c|}{ Study group } & \multicolumn{2}{|c|}{ Control group } & \multirow[t]{2}{*}{$P$ value } \\
\hline & Count & $\%$ & Count & $\%$ & \\
\hline \multicolumn{6}{|c|}{ Age in years } \\
\hline$<20$ & 10 & $12.70 \%$ & 79 & $11.70 \%$ & \multirow{5}{*}{0.136} \\
\hline $20-30$ & 41 & $51.90 \%$ & 365 & $53.90 \%$ & \\
\hline $31-40$ & 17 & $21.50 \%$ & 167 & $24.70 \%$ & \\
\hline$>40$ & 11 & $13.90 \%$ & 66 & $9.70 \%$ & \\
\hline Total & 79 & $100.00 \%$ & 677 & $100.00 \%$ & \\
\hline \multicolumn{6}{|c|}{ GA in weeks at diagnosis } \\
\hline $28-32$ & 19 & $24.10 \%$ & 140 & $20.70 \%$ & \multirow{4}{*}{0.89} \\
\hline $33-36$ & 37 & $46.80 \%$ & 345 & $50.90 \%$ & \\
\hline $37-40$ & 23 & $29.10 \%$ & 192 & $28.40 \%$ & \\
\hline Total & 79 & $100.00 \%$ & 677 & $100.00 \%$ & \\
\hline \multicolumn{6}{|c|}{ Party } \\
\hline$P G$ & 38 & $48.10 \%$ & 340 & $50.20 \%$ & \multirow{4}{*}{$0.00^{*}$} \\
\hline Multipara & 24 & $30.40 \%$ & 192 & $28.40 \%$ & \\
\hline Grandmultipara & 17 & $21.50 \%$ & 145 & $21.40 \%$ & \\
\hline Total & 79 & $100.00 \%$ & 677 & $100.00 \%$ & \\
\hline \multicolumn{6}{|c|}{ Gestational age at delivery } \\
\hline Preterm & 19 & $24.10 \%$ & 74 & $10.90 \%$ & \multirow{3}{*}{$0.000^{*}$} \\
\hline Term & 60 & $75.90 \%$ & 603 & $89.10 \%$ & \\
\hline Total & 79 & $100.00 \%$ & 677 & $100.00 \%$ & \\
\hline
\end{tabular}

*Statistically significant at 0.05 level

Table 3: Shows the nonparametric correlation between the two group regarding maternal and fetal outcome.

\begin{tabular}{|c|c|c|c|c|c|}
\hline \multirow{2}{*}{} & Study group & \multicolumn{2}{c|}{ Control group } & \multirow{2}{*}{ P value } \\
\cline { 2 - 6 } & Count & $\%$ & Count & \\
\hline \multicolumn{7}{|c|}{ Maternal complications } \\
\hline Placental abruption & 5 & $6.40 \%$ & 15 & $2.20 \%$ & $0.00^{*}$ \\
\hline
\end{tabular}




\begin{tabular}{|c|c|c|c|c|c|}
\hline $\mathrm{PPH}$ & 11 & $13.70 \%$ & 21 & $3.10 \%$ & $0.02^{*}$ \\
\hline DIC & 5 & $6.40 \%$ & 8 & $1.20 \%$ & $0.01^{*}$ \\
\hline Rectus sheath hematoma & 4 & $5.10 \%$ & 3 & $0.40 \%$ & $0.00^{*}$ \\
\hline Acute renal failure & 1 & $1.30 \%$ & 0 & $0.00 \%$ & $0.00^{*}$ \\
\hline Puerperal sepsis & 5 & $6.40 \%$ & 3 & $0.40 \%$ & $0.05^{*}$ \\
\hline No complications & 48 & $60.70 \%$ & 627 & $92.70 \%$ & $0.01^{*}$ \\
\hline Total & 79 & $100.00 \%$ & 677 & $100.00 \%$ & \\
\hline \multicolumn{6}{|c|}{ Perinatal outcome } \\
\hline Still birth & 5 & $6.40 \%$ & 15 & $2.20 \%$ & $0.02^{*}$ \\
\hline IUGR & 8 & $10.10 \%$ & 13 & $1.90 \%$ & $0.04^{*}$ \\
\hline Birth asphyxia & 8 & $10.10 \%$ & 17 & $2.50 \%$ & $0.00^{*}$ \\
\hline Neonatal thrombocytopenia & 4 & $5.10 \%$ & 0 & $0.00 \%$ & $0.01^{*}$ \\
\hline No & 54 & $68.30 \%$ & 632 & $93.40 \%$ & $0.00^{*}$ \\
\hline Total & 79 & $100.00 \%$ & 677 & $100.00 \%$ & \\
\hline \multicolumn{6}{|c|}{ Mode of delivery } \\
\hline Vaginal delivery & 59 & $74.70 \%$ & 418 & $61.70 \%$ & $0.01^{*}$ \\
\hline Caesarian section & 19 & $24.10 \%$ & 251 & $37.10 \%$ & $0.00^{*}$ \\
\hline Instrumental vaginal delivery & 1 & $1.20 \%$ & 8 & $1.20 \%$ & 0.14 \\
\hline Total & 79 & $100.00 \%$ & 677 & $100.00 \%$ & \\
\hline \multicolumn{6}{|c|}{ Neonatal nursery admission } \\
\hline Yes & 25 & $31.60 \%$ & 94 & $13.90 \%$ & \multirow{3}{*}{$0.02^{*}$} \\
\hline No & 54 & $68.40 \%$ & 583 & $86.10 \%$ & \\
\hline Total & 79 & $100.00 \%$ & 677 & $100.00 \%$ & \\
\hline \multicolumn{6}{|c|}{ Hospital stay (days) } \\
\hline 1-3 days & 32 & $40.5 \%$ & 603 & $89.10 \%$ & \multirow{3}{*}{$0.01^{*}$} \\
\hline$>3$ days & 47 & $59.5 \%$ & 74 & $10.90 \%$ & \\
\hline Total & 79 & $100.00 \%$ & 677 & $100.00 \%$ & \\
\hline
\end{tabular}

*Statistically significant at 0.05 level

\section{Discussion}

Thrombocytopenia is second to anemia as the most common hematologic abnormality encountered during pregnancy. In this study, the prevalence of thrombocytopenia among the pregnant women was $10.4 \%$. This figure is similar to studies conducted in Sudan $(8.8 \%)$ and $(8.8 \%)$ in Iraq $[9,10]$. However, our result is lower than studies conducted in Ghana (15.3\%) and Nigeria $(13.5 \%)[11,12]$.

Among the thrombocytopenic pregnant women included in the present study, (65.8\%) of the women had mild thrombocytopenia while $22(27.8 \%)$ and $5(6.4 \%)$ of women were moderate and severe thrombocytopenic respectively. These results are the same with the study conducted in Iraq [10] and it also agrees with studies conducted in Ghana and Nigeria which showed the presence of high frequency of mild thrombocytopenia $[11,12]$.

The present study revealed that, gestational thrombocytopenia accounts for the majority of thrombocytopenia's and is characterized by mild thrombocytopenia, which correlate with other studies [11-13]. More over our study demonstrated gestational thrombocytopenia not associated with any adverse events for either the mother or baby and requires no specific treatment; but the other etiologies must be excluded (i.e. megaloblastic anemia, immune thrombocytopenia, eclampsia, and liver disorders) before labeling the patient as gestational thrombocytopenia.

Also, our study demonstrates other cases of thrombocytopenia due to preeclampsia and HELLP syndrome. Other causes were febrile conditions like malaria which are endemic in our area and some rare causes include DIC, ITP.

In our study $24.1 \%$ of subjects had delivered by LSCS and $75.9 \%$ patient delivered vaginally which was not similar to study by Singh et al (LSCS 36\% and NVD 64\%) but comparable to Ruggri, et al. [14-15] (LSCS 20\% and NVD 80\%). Whereas the incidence of LSCS was higher in the studies conducted by Pafumi et al (55\%) and Yuce et al (56\%) [16-17].

The present study demonstrated that pregnant women with thrombocytopenia had significantly higher maternal and neonatal morbidity than did control group. The major maternal complications in our study were placental abruption, PPH, DIC, rectus sheath hematoma, acute renal failure and puerperal sepsis, while preterm deliveries, birth asphyxia, IUGR, and stillbirths were most neonatal complications seen in thrombocytopenia group. 
Also, Yuce T et al [16], found that pregnancy outcomes with thrombocytopenia associated with poor maternal and neonatal outcome. Our finding is correlate with Yuce T and comparable with Pafumi C, et al. [17]. However, contrary to our findings, Ruggeri M, et al. [15], did not find any differences in the rates of blood transfusion requirements, or postpartum haemorrhage.

Early neonatal thrombocytopenia was present in 5\% of study group in present study, which is slightly higher than figure quoted by Parnas, et al. [18] (3.5\%) neonates had moderate to severe thrombocytopenia.

Furthermore, neonatal outcome was controversial in previous studies, particularly the risk of fetal asphyxia. Yuce $\mathrm{T}$ [16], and Parnas et al. [18], found no difference in the risk of fetal asphyxia.

Limitation of our study is that, long-term psychological and physical maternal morbidity were not evaluated well. Further studies should be done with proper involvement of long-term psychological and physical maternal morbidity. Another limitation was that the study was used small sample size. Patient selection, sampling, intervention and data collection all done by the same observer.

\section{Conclusion}

The common causes of thrombocytopenia in pregnancy are gestational thrombocytopenia, preeclampsia, (ITP), HELLP syndrome and malaria. Gestational thrombocytopenia is associated with better maternal and perinatal outcome as compared to pre-eclampsia, HELLP syndrome, ITP which expose them to life threatening complications as placental abruption, post-partum hemorrhage, birth asphyxia and stillbirth.

\section{Acknowledgement}

None.

\section{Conflict of Interest}

No conflict of interest.

\section{References}

1. Kadir RA, McLintock C (2011) Thrombocytopenia and disorders of platelet function in pregnancy. Semin Thromb Hemost. 37(6): 640-652.

2. McCarae KR (2010) Thrombocytotenia in pregnancy. Hematology Am Soc Hematol Educ Program 2010: 397-402.
3. Sullivan CA, Martin JN Jr (1995) Management of the obstetric patients with thrombocytopenia. Clin Obstet Gynecol 38(3): 521-534.

4. Magann EF, Martin JN (1999) Twelve steps to optical management of HELLP syndrome. Clin Obstet Gynecol 42(3): 532-550.

5. Karim R, Sacher RA (2004) Thrombocytopenia in pregnancy. Curr Hematol Rep 3(2): 128-133.

6. Cunningham FG, Gant NF, Leveno KJ, Gilstrap LC, Hauth JC, et al. (2001) Williams obstetrics. (21 ${ }^{\text {st }}$ edn), McGraw-Hill, Hematological disorders p. 1307-1338.

7. Shehata N, Burrow RF, Kelton JG (1999) Gestational thrombocytopenia. Clin Obstet Gynecol 42(2): 327-334.

8. Cines DG, Blanchette VS (2002) Immune thrombocytopenic purpura. N Engl J Med 346(13): 995-1008.

9. Elgari MM (2013) Evaluation of hematological parameters of Sudanese pregnant women attending at Omdurman al Saudi maternity hospital. Egypt Acad J Biolog Sci 5(1): 37-42.

10. Shamoon RP, Muhammed NS, Jaff MS (2009) Prevalence and etiological classification of thrombocytopenia among a group of pregnant women in Erbil City, Iraq. Turk J Hematol 26(3): 123-128.

11. Olayemi E, Akuffo FW (2012) Gestational thrombocytopenia among pregnant Ghanaian women. Pan Afr Med J 12: 34.

12. Ajibola SO, Akinbami A, Rabiu K, Adewunmi A, Dosunmu A, et al. (2014) Gestational thrombocytopenia among pregnant women in Lagos, Nigeria. Niger Med J 55 (2): 139-143.

13. Vyas RC, Shah SC, Yadav PA, Patel UK (2014) Comparative study of mild versus moderate to severe thrombocytopenia in third trimester of pregnancy in a tertiary care hospital. NHL Journal of Medical Sciences 3(1): 8-11.

14. Singh N, Amita D, Uma S, Tripathi AK, Pushplata S (2012) Prevalence and characterization of thrombocytopenia in pregnancy in Indian women. Indian J Hematol Blood Transfus 28(2): 77-81.

15. Ruggeri M, Schiavotto C, Castaman G, Tosetto A, Rodeghiero F (1997) Gestational thrombocytopenia: a prospective study. Haematologica 82(3): 341-342.

16. Yuce T, Acar D, Kalafat E, Alkilic A, Cetindag E, et al. (2014) Thrombocytopenia in pregnancy: do the time of diagnosis and delivery route affect pregnancy outcome in parturients with idiopathic thrombocytopenic purpura? Int J Hematol 100(6): 540-544.

17. Pafumi C, Valenti O, Giuffrida L, Colletta G (2013) Gestational thrombocytopenia: does it cause any maternal and /or perinatal morbidity? Cukurova Med J 38(3): 349-57.

18. Parnas M, Sheiner E, Shoham-Vardi I, Burstein E, Yermiahu T, et al. (2006) Moderate to severe thrombocytopenia during pregnancy. Eur J Obstet Gynecol Reprod Biol 128 (1-2): 163-68. 